\title{
A Phase 1 Trial of Oncolytic Adenovirus ICOVIR-5 Administered Intravenously to Cutaneous and Uveal Melanoma Patients
}

\author{
Margarita García, ${ }^{1, \dagger}$ Rafael Moreno, ${ }^{2, \dagger}$ Marta Gil-Martin, ${ }^{3}$ Manel Cascallò, ${ }^{2,4}$ \\ Maria Ochoa de Olza, ${ }^{3}$ Carmen Cuadra, ${ }^{1}$ Josep Maria Piulats, ${ }^{3}$ Valentin Navarro, \\ Marta Domenech, ${ }^{3}$ Ramon Alemany, ${ }^{2, *}$ and Ramon Salazar ${ }^{3}$ \\ ${ }^{1}$ Clinical Research Unit, ${ }^{2}$ ProCure and Oncobell Programs, and ${ }^{3}$ Department of Medical Oncology, Oncobell Program, Institut Català d'Oncologia-IDIBELL, \\ $L^{\prime}$ Hospitalet, Barcelona, Spain; ${ }^{4}$ VCN Biosciences, Sant Cugat del Valles, Barcelona, Spain. \\ $\dagger M$. Garcia and R. Moreno contributed equally to this work.
}

\begin{abstract}
Oncolytic viruses represent a unique type of agents that combine self-amplification, lytic, and immunostimulatory properties against tumors. A local and locoregional clinical benefit has been demonstrated upon intratumoral injections of an oncolytic herpes virus in melanoma patients, leading to its approval in the United States and Europe for patients without visceral disease (up to stage IVM1a). However, in order to debulk and change the local immunosuppressive environment of tumors that cannot be injected directly, oncolyitc viruses need to be administered systemically. Among different viruses, adenovirus has been extensively used in clinical trials but with few evidences of activity upon systemic administration. Preclinical efficacy of a single intravenous administration of our oncolytic adenovirus ICOVIR5, an adenovirus type 5 responsive to the retinoblastoma pathway commonly deregulated in tumors, led us to use this virus in a dose-escalation phase 1 trial in metastatic melanoma patients. The results in 12 patients treated with a single infusion of a dose up to $1 \times 10^{13}$ viral particles show that ICOVIR5 can reach melanoma metastases upon a single intravenous administration but fails to induce tumor regressions. These results support the systemic administration of armed oncolytic viruses to treat disseminated cancer.
\end{abstract}

Keywords: oncolytic, adenovirus, melanoma, trial

\section{INTRODUCTION}

MALIGNANT MELANOMA REPRESENTS the ninth most common tumor in Europe, with more than 100,000 new cases registered in $2012 .{ }^{1}$ In advanced stages, the only approved chemotherapy is dacarbazine, which has a response rate of around $10 \% .^{2} \mathrm{Re}-$ cently, several treatments have been approved that specifically target melanoma tumors with $B R A F$ V600E or V600K mutations or block some forms of MEK. ${ }^{3-5}$ Immune checkpoint blockers ipilimumab, pembrolizumab, and nivolumab are also treatments recently approved due to their ability to improve overall survival. ${ }^{6-8}$ Additionally, talimogene laherparepvec, a genetically modified oncolytic herpes simplex virus type 1, which secrets granulocyte-macrophage colony stimulating fac- tor, is approved for local intralesional injection based on data that demonstrated shrinkage of lesions, showing the plausibility of a strategy based on oncolysis and immune system stimulation by viruses. ${ }^{9}$

Oncolytic adenovirus-based therapy remains a promising approach to cancer treatment, as the virus can infect tumor cells and selectively replicate in them, leading to oncolysis and release of new viruses, which conduct to local and bloodstream spread and finally to induction of an immune reaction against the tumor. ${ }^{10,11}$ The existing experience with intravenous administration of oncolytic virus shows that high doses of adenovirus ( $\geq 10^{13}$ viral particles) in more than 300 cancer patients resulted in limited efficacy with mild toxicity

*Correspondence: Dr. Ramon Alemany, ProCure Program, Institut Català d'Oncologia, Avinguda Gran Via de I'Hospitalet 199-203, L'Hospitalet de Llobregat, Barcelona 08907, Spain.E-mail: ralemany@iconcologia.net 
characterized by a transient febrile peak, elevation of transaminases, and occasionally moderate transient nausea and flu-like symptoms.

ICOVIR-5 is derived from the oncolytic adenovirus Ad- $\Delta 24$ arginine-glycine-aspartic acid (RGD), ${ }^{12}$ which contains two modifications, compared with wild type Ad5: first, the E1A region responsible for retinoblastoma $(\mathrm{pRB})$ protein binding is deleted to abrogate the capability of early 1 A (E1A) to release E2F from the pRB-E2F complex, characteristic of quiescent cells, contributing to the preferential replication of the virus in tumor and dividing cells. Second, an RGD sequence inserted at the HI loop of the fiber knob to target integrins at the surface of cancer cells as a primary receptor for virus entry. Two additional modifications were present in ICOVIR- $5^{13}$ : replacement of the E1A promoter by the human E2F-1 promoter (insulated from the E1A enhancer using the myotonic dystrophy insulator, DM-1) and a consensus Kozak sequence inserted before the first codon of the $E 1 A$ gene to boost E1A mRNA translation.

The main objective of this first-in-human study was to determine the maximum tolerated dose (MTD) of the infusion of conditionally replicating oncolytic adenovirus ICOVIR-5 in patients with advanced malignant melanoma. Secondary objectives were recommended dose, safety, toxicity profile, and preliminary efficacy data, if any.

\section{MATERIALS AND METHODS}

This phase 1 trial of ICOVIR-5 was conducted at the Catalan Institute of Oncology (Barcelona, Spain) in accordance with the Declaration of Helsinki and the Principles of Good Clinical Practice, and it was approved by The Clinical Research Ethics Committee of the Bellvitge University Hospital and the Spanish Medicines and Sanitary Products Agency Trial Ref EudraCT 2008-005694-35. All participants provided written informed consent. This study was registered at clinicaltrials.gov with the identifier NCT01864759.

\section{Patients}

Eligible patients had uveal or cutaneous metastatic malignant melanoma. Patients could have received any prior treatment for metastatic disease. Inclusion criteria were histological proof of cancer, age $\geq 18$ years, performance status 0 to 2 (Eastern Cooperative Oncology Group scale), absolute neutrophil count greater than or equal to $1500 / \mu \mathrm{L}$, platelet count greater than or equal to $100,000 / \mu \mathrm{L}$, normal function of the liver (bilirubin level < the upper limits of normal [ULN], aspartate aminotransferase (AST)/alanine transaminase level $\leq 2.5$ times the ULN, alkaline phosphatase level $<2.5$ times the ULN) and kidney (creatinine clearance $\geq 50 \mathrm{~mL} / \mathrm{min}$ ), and negative HIV serology. Patients with previous participation in studies with adenovirus, viral syndrome diagnosed 2 weeks before inclusion, concomitant chronic immunosuppressant medication, concomitant malignant hematology disease, Li Fraumeni Syndrome, or germ line deficit pRb pathway were excluded.

\section{Study design}

The study was conducted using an accelerated escalating phase 1 design with cohorts of 1 patient if no grade $>2$ toxicity was found, and then with 3-6 patient cohorts after the first grade 3 toxicity finding. A dose-limiting toxicity (DLT) observation period of 4 weeks was established before the entry of the first patient at the next dose level. If one out of three patients experienced DLT during the treatment cycle, at least one more additional patient was to be treated at this dose level, and up to six patients could be sequentially treated at this dose level. The maximum tolerated dose (MTD) was defined as the dose level at which two of the three to six treated patients experienced DLT, and the recommended dose (RD) was the highest dose level at which fewer than 2 of 6 patients experienced DLT. Toxicity was classified according to the common toxicity criteria of the National Cancer Institute (NCI CTC, version 3.0). DLT was defined as: absolute neutrophil count $<0.5 \times 10^{9}$ per liter for more than 5 days, febrile neutropenia as defined by the NCI CTC 3.0, platelet count $<25 \times 10^{9}$ per liter, any other nonhematologic grade 3-4 toxicity except for alopecia, nausea/vomiting unresponsive to specific treatment, or any toxicity grade 2 unrecovered at 6 weeks of treatment.

\section{Treatment}

ICOVIR-5 was administered as a single infusion in an inpatient regimen. Before administration, ICOVIR-5 was thawed and diluted in $50 \mathrm{~mL} 0.9 \%$ $\mathrm{NaCl}$ for intravenous administration. Patients were monitored in a specific isolation room at the hospital until acute events were solved.

Dose levels: $1 \mathrm{a}, 1 \times 10^{11}$ viral particles (vp); $2 \mathrm{a}$, $3.3 \times 10^{11} \mathrm{vp}$; $3 \mathrm{a}, 1 \times 10^{12} \mathrm{vp}$; $4 \mathrm{a}, 3.3 \times 10^{12} \mathrm{vp}$; and $5 \mathrm{a}$, $1 \times 10^{13} \mathrm{vp}$. A dose level of $1 \times 10^{10}(-1 \mathrm{a})$ was planned if dose 1a became limiting.

\section{Study assessments}

All patients were evaluated by physical examination, ECG, and chest X-ray. Complete blood cell count, liver and kidney function tests, and urine 
analysis were obtained before treatment on days 1 , $2,3,5,12,19$, and at the end of the study (day 26). Study of extent of disease was performed by computed tomography or magnetic resonance imaging of the chest, liver, and abdomen and bone scan with $\mathrm{x}$-ray if hot spots were observed. Assessments of tumor lesions were made at 4 weeks of treatment, applying the criteria recommended for evaluation of response in solid tumors (RECIST 1.1). Tumor biopsies were obtained if feasible at the beginning of the study and at day 5 posttreatment.

\section{ICOVIR-5}

ICOVIR- 5 has been previously described..$^{13}$ It derives from the oncolytic adenovirus Ad- $\triangle 24 \mathrm{RGD},{ }^{12}$ currently in clinical trials against glioblastoma under the name DNX-2401 (DNAtrix Therapeutics, Houston, TX). ICOVIR-5 was constructed by homologous recombination in bacteria and transfection in HEK293 cells. Then, it was plaque-purified and amplified in A549 cells and purified using a $\mathrm{CsCl}$ gradient. The viral genomic structure was verified by restriction analysis. The DM-1 insulator, E2F-1 promoter, Kozak sequence, E1A- $\Delta 24$ deletion, and RGD fiber were sequenced. The clinical batch of ICOVIR-5 was manufactured at the Center for Cell and Gene Therapy at Baylor College of Medicine (Houston, TX) under good manufacturing practices (GMP) conditions using A549 cells. Virus titer was adjusted to $1 \times 10^{12} \mathrm{vp} / \mathrm{mL}$ in $20 \mathrm{mM}$ Tris $\mathrm{pH} 8.0$, $25 \mathrm{mM} \mathrm{NaCl}, 2.5 \%$ glycerol; aliquoted in sterile vials; and stored at $-80^{\circ} \mathrm{C}$ with continuous temperature monitoring. Functional virus titer was $5.33 \times 10^{10}$ plaque-forming units/mL, which corresponds to 18.7 virus particles/functional particle bioactivity ratio. No wild type Ad5 or other adventitious viruses were detected by PCR.

\section{Virus pharmacokinetics}

Immediately after the end of virus administration (time 0 ), and at $30 \mathrm{~min}, 1 \mathrm{~h}, 2 \mathrm{~h}, 4 \mathrm{~h}, 6 \mathrm{~h}$, and $24 \mathrm{~h}$ after virus administration, blood samples were taken using $4 \mathrm{~mL}$ Lithium Heparin Vacuette tubes (Greiner Bio-One, Monroe, NC), and total DNA was isolated by the QIAamp DNA Mini and QIAamp DNA Blood Mini Kits (QIAGEN, Valencia, CA) in triplicate according to the manufacturer protocol. Four microliters of DNA were used to quantify genome copy number by quantitative real-time PCR using ICOVIR-5-specific primers (ICO5F2-5'-GAT TTG GCG CGT AAA AGT G -3', which overlaps E2F1 promoter, and the reverse ICO5R2-5'-CGG CCA TTT CTT CGG TAA TA-3', which overlaps with the E1A gene, generating a $126 \mathrm{bp}$ amplicon). Real- time PCR consisting of $10 \mathrm{~min}$ at $95^{\circ} \mathrm{C}$ and 40 cycles $\left(95^{\circ} \mathrm{C}, 15 \mathrm{~s} ; 60^{\circ} \mathrm{C} \mathrm{s} ; 72^{\circ} \mathrm{C}, 10 \mathrm{~s}\right)$ was performed on the LightCycler $^{\circledR} 480$ II (Roche, Basel, Switzerland), using LightCycler 480 SYBR Green I Master (Roche) and analyzed with LightCycler ${ }^{\circledR} 480$ Software release 1.5.0 SP4 (Roche). A control PCR without DNA was included to monitor reagent contamination.

For genome copy quantification, blood from a donor was spiked with a 10 -fold serial dilution of ICOVIR-5 to generate a standard curve from $1 \times 10^{10} \mathrm{vp} / \mathrm{mL}$ to $1 \times 10^{2} \mathrm{vp} / \mathrm{mL}$. This curve and negative controls of blood without virus were processed with the same protocol as patient samples and analyzed in the same real-time PCR to quantify genome copies. Precision, accuracy, and limits of detection (LOD) and quantification (LOQ) were established using the standard curve in a previous experiment. LOD, the lowest concentration of genomes in the standard curve that can be detected, was $1 \times 10^{3}$ genomes/mL. LOQ, the lowest concentration of genomes in the standard curve which maintains linearity with the standard curve (slope $0.8-1.2$ ), was $1 \times 10^{4}$ genomes $/ \mathrm{mL}$.

\section{Analysis of virus shedding}

Blood, urine, sputum, and stool samples were collected before administration and on days 1, 2, 5, 12,19 , and 26 posttreatment. Samples were analyzed when available due to compliance of protocols. Among them, sputum and stool presented a higher frequency of lack of compliance. DNA was extracted with the following kits: QIAamp DNA Mini and QIAamp DNA Blood Mini Kits for blood; QIAamp Viral RNA Mini kit for urine after concentration with Millipore Amicon Ultra Centrifugal Filters Ultracel 50k (Millipore; Darmstadt, Germany); QIAampMinElute Virus Spin for sputum; and QIAamp DNA Stool for stool (all kits from QIAGEN). All samples were processed in triplicate.

A 10-fold serial dilution standard curve for each type of sample was generated diluting ICOVIR-5 in the corresponding sample obtained from nontreated donors. Standard curves and negative controls (samples without virus) were processed as patient samples.

Isolated DNA $(4 \mu \mathrm{L})$ were used to quantify the genome copy number using the same quantitative real-time PCR program described above for pharmacokinetics.

The LOQ and LOD were previously determined for the different samples. For blood, LOQ and LOD were the same described above for pharmacokinetics. For urine, LOQ and LOD were established as $1.25 \times 10^{4}$ genomes $/ \mathrm{mL}$. For sputum, LOD $1 \times 10^{3}$ genomes $/ \mathrm{mL}$ and LOQ was $1 \times 10^{4}$ genomes $/ \mathrm{mL}$. 
For stool LOD was $1 \times 10^{3}$ genomes/g and LOQ was $1 \times 10^{4}$ genomes/g.

\section{ICOVIR-5 genomes in tumor biopsies}

Patient tumor biopsies were obtained when possible by core needle biopsy from accessible skin lesions at day 5 posttreatment to detect ICOVIR-5. Samples were digested with proteinase $\mathrm{K}$ and DNA extracted using QIAamp DNA Mini and QIAamp DNA Blood Mini Kits according to the manufacturer instructions. A 10-fold serial dilution standard curve was generated diluting ICOVIR-5 with sterile phosphate-buffered saline (Life Technologies, Carlsbad, CA) and processed as tumor samples.

Isolated DNA $(4 \mu \mathrm{L})$ were used to quantify the genome copy number using the same quantitative real-time PCR program as above for pharmacokinetics. The LOD was $10^{3}$ genomes/sample and the LOQ $10^{4}$ genomes/sample.

\section{Analysis of cytokines in blood}

Cytokines IL6 and IL10 were chosen for the analysis as possible predictors of immunologic response and toxicity. Basal and post-treatment levels $(6 \mathrm{~h}, 24 \mathrm{~h}, 48 \mathrm{~h}$, day 5 , day 12 , day 19 , and day 26) of cytokines IL6 and IL10 in patient serum were quantified using ELISA assays (R\&D; Minneapolis, MN). Patient peripheral blood was collected in Vacuette Z Serum Sep Clot Activator tubes (Greiner Bio-One, Monroe, NC), allowed to coagulate for $30 \mathrm{~min}$ and centrifuged at $1500 \mathrm{~g}$ for $10 \mathrm{~min}$. Serum samples were harvested and stored at $-80^{\circ} \mathrm{C}$ until analysis. ELISA assays were carried out according to manufacturer's protocols. Each sample was analyzed in triplicate.

\section{Anti-ICOVIR-5 neutralizing antibodies}

Neutralizing antibodies in serum against adenovirus type 5 were analyzed before treatment and at day 19 after ICOVIR-5 administration. Samples of serum were heated at $56^{\circ} \mathrm{C}$ for $30 \mathrm{~min}$ in order to inactivate complement. A 2-fold serial dilution of inactivated samples from $1 / 10$ to $1 / 5120$ was performed in Dulbecco's modified Eagle's medium in 96well plates (final volume $50 \mu \mathrm{L}$ ) in quadruplicates. Serum dilutions were incubated for $1 \mathrm{~h}$ at room temperature with $2.5 \times 10^{4}$ transducing units of AdTL, an adenovirus type 5 E1-deleted vector expressing luciferase and enhanced green fluorescent protein (EGFP). ${ }^{14}$ Afterwards $1 \times 10^{5}$ HEK-293 cells per well were added (to obtain a proportion or multiplicity of infection of 0.25 transducing units/cell) and cultured at $37^{\circ} \mathrm{C}$ and $5 \% \quad \mathrm{CO}_{2}$. After $24 \mathrm{~h}$ of infection, media was removed and cells were washed once with phosphate-buffered saline. Finally, the level of luciferase in each sample was quantified using a Victor X5 Multilabel Plate Reader (Perki nElmer, Waltham, MA). The percentage of neutralization was calculated with the formula (\% neutralization $=[1-(($ LUsample-LUnegative control $) /$ (LUpositive control-LUnegative control))] $\times 100$.

As a negative control we used the luciferase units (LU) of a noninfected well, and as a positive control we used the LU of an infected well without serum. The neutralizing antibody titers were expressed as the reciprocal of the serum dilution closest to $50 \%$ neutralization of the infection. Every serum sample was quantified in quadruplicate.

\section{Statistical analysis}

Descriptive statistics were used for safety analyses for all patients who received one dose of ICOVIR-5. Categorical and continuous data were summarized with frequencies and percentages. The efficacy population included all patients with a baseline assessment and a post-baseline tumor assessment. Fisher's exact test was used to correlate neutralizing antibodies with clinical responses and linear regression analysis to correlate viral doses with cytokine levels.

\section{RESULTS}

\section{Patient characteristics, tolerability, and efficacy}

Thirteen patients were enrolled in the study and twelve were treated at five dose levels (Table 1). Patient 05 was screened but not treated due to early progression. All 12 treated patients were evaluable for toxicity. Patients' characteristics were as follows: 7 males and 5 females, median age 51 years (range 40-80), and Eastern Cooperative Oncology Group performance status of 0 (5 patients) or 1 ( 7 patients). All patients had evaluable or measurable disease. Six patients $(50 \%)$ had received at least one prior chemotherapy regimen for metastatic melanoma, and 4 (33\%) patients had received previous immunotherapy (Supplementary Table S1). Six patients had uveal melanoma and six had cutaneous melanoma. All patients received one treatment injection and were observed for 4 weeks, except for one (patient 2 ) who did not complete one cycle of observation due to early progression. This patient (2), following the protocol, was replaced, although he was considered evaluable for toxicity. In the context of a rapid progression, patient 2 presented a 
Table 1. Dose levels and dose-limiting toxicities

\begin{tabular}{|c|c|c|c|c|c|}
\hline $\begin{array}{l}\text { Patient } \\
\text { No. }\end{array}$ & Dose (vp) & Level & Toxicity & $D L T$ & Decision taken by Investigators' Committee \\
\hline 01 & $1 \times 10^{11}$ & $1 \mathrm{a}$ & $\begin{array}{l}\text { Grade } 3 \text { lymphopenia } \\
\text { Grade } 2 \text { neutropenia }\end{array}$ & No & $\begin{array}{l}\text { Grade } 3 \text { toxicity not associated to treatment } \\
\text { Decision: escalation to the next level }\end{array}$ \\
\hline 02 & $3.3 \times 10^{11}$ & $2 a$ & Grade 3 asthenia & No & The patient did not complete the cycle. Decision: replacement of patient \\
\hline 03 & $3.3 \times 10^{11}$ & $2 a$ & Grade 1 toxicity & No & Decision: escalation to the next level \\
\hline 04 & $1 \times 10^{12}$ & 3a & Grade 2 thrombocytopenia & No & Grade 3 thrombocytopenia out of the cycle. By relevance, the decision is replacement of patient. \\
\hline 06 & $1 \times 10^{12}$ & 3a & Grade 3 neutropenia & No & $\begin{array}{l}\text { Transient ( }<24 \text { hours) grade } 3 \text { toxicity. } \\
\text { Decision: escalation to the next level }\end{array}$ \\
\hline 07 & $3.3 \times 10^{12}$ & $4 a$ & $<$ Grade 2 toxicity & No & $\begin{array}{l}\text { Grade } 2 \text { unrelated asthenia } \\
\text { Decision: escalation to the next level }\end{array}$ \\
\hline 08 & $1 \times 10^{13}$ & $5 a$ & $\begin{array}{l}\text { Grade } 3 \text { transaminitis } \\
\text { Grade } 3 \text { thrombocytopenia }\end{array}$ & Yes & Expansion of cohort by DLT \\
\hline 09 & $1 \times 10^{13}$ & $5 a$ & & No & \\
\hline 10 & $1 \times 10^{13}$ & $5 a$ & & No & \\
\hline 11 & $1 \times 10^{13}$ & $5 a$ & & No & \\
\hline 12 & $1 \times 10^{13}$ & $5 a$ & & No & \\
\hline 13 & $1 \times 10^{13}$ & $5 a$ & Grade 3 transaminitis & Yes & $\begin{array}{l}\text { End of study due to two DLT. } \\
\text { Maximum tolerated dose declared level }\end{array}$ \\
\hline
\end{tabular}

DLT, dose limiting toxicity; vp, viral particles.

disseminated intravascular coagulation not related to the treatment, but rather, to the progression of the underlying disease.

Table 2 lists the most significant all-cycle nonhematological toxicities observed in the study. At dose levels 1a-3a, no relevant toxicity was observed. The unrelated grade 2 asthenia observed at level 4 a did not block dose escalation. Acute toxicity was mainly a flu-like syndrome with fever, chills, arthromyalgia, headache, nausea, and vomiting, and diarrhea, which began in the first 4-6 hours after infusion and during 2-4 days. The first pa-

Table 2. Number of patients with nonhematologic toxicity, considering the worst grade toxicity for each patient $(\mathrm{n}=12)$

\begin{tabular}{lllll}
\hline & \multicolumn{4}{c}{ Toxicity (grade) } \\
\cline { 2 - 5 } Symptoms & 1 & 2 & 3 & 4 \\
\hline Fever & 8 & 1 & 0 & 0 \\
Stomatitis & 1 & 1 & 0 & 0 \\
Myalgia/arthralgia & 2 & 1 & 0 & 0 \\
Headache & 1 & 0 & 0 & 0 \\
Asthenia & 4 & 2 & 1 & 0 \\
Rash & 2 & 0 & 0 & 0 \\
Diarrhea & 1 & 0 & 0 & 0 \\
Constipation & 1 & 0 & 0 & 0 \\
Hypertension & 1 & 1 & 0 & 0 \\
Edema & 1 & 0 & 1 & 0 \\
Nausea/ Vomiting & 2 & 0 & 0 & 0 \\
Renal failure & 0 & 1 & 0 & 0 \\
Chills & 2 & 0 & 0 & 0 \\
Transaminitis & 0 & 1 & 2 & 0 \\
Hypocalcemia & 0 & 1 & 0 & 0 \\
Hypophosphatemia & 0 & 1 & 0 & 0 \\
Hypomagnesemia & 1 & 0 & 0 & 0 \\
Hypokalemia & 1 & 0 & 0 & 0 \\
\hline
\end{tabular}

tient at the level 5a (patient 08) experienced toxicity as transaminitis grade 3 at day +1 . In addition, this patient presented grade 3 thrombocytopenia at day +4 . On day +2 , transaminitis was recovered to grade 1 and thrombocytopenia lasted to day +12 . This dose level was then expanded to 6 patients. Patient 13 presented the second DLT as hepatic grade 3 toxicity (grade 3 AST elevation which lasted 2 days and recovered to grade 0 at day +12 ). Both patients had normal transaminases levels before treatment, and only patient $08 \mathrm{had}$ metastatic liver involvement at the beginning of the study. According to protocol, this level (5a, $1 \times 10^{13}$ ) was declared MTD, and the recommended phase 2 dose was defined at the inferior dose level $4 \mathrm{a}\left(3.3 \times 10^{12}\right)$. Other significant toxicities at this dose level included grade 2 neutropenia in patient 08 and grade 2 AST elevation in both patients.

With regard to efficacy, the 11 patients who had received treatment and had undergone at least one disease evaluation (performed day 26) were evaluated. No objective responses, partial or complete, were observed. At the lower dose levels 2 patients had stable disease: patient 03 until day 100 posttreatment and patient 06 until day 433 after treatment. At the highest dose level $\left(1 \times 10^{13} \mathrm{vp}\right)$, stable disease was observed in 5 out of 6 patients: patient 09 until day 56, patient 010 until day 94, patient 011 until day 131, patient 012 until day 84, and patient 013 until day 112 posttreatment (Table 3). Comparing the survival of cutaneous melanoma patients that never received targeted therapy or anti-PD1 antibodies after participating in the trial versus uveal melanoma patients, the 
Table 3. Anti-Ad5 neutralizing antibodies, clinical responses, and viral genomes in biopsies

\begin{tabular}{lccclll}
\hline Patient No. & Dose & Basal NAbs & $\begin{array}{c}\text { NAbs after } \\
\text { treatment (d19) }\end{array}$ & $\begin{array}{c}\text { Clinical } \\
\text { response }\end{array}$ & $\begin{array}{c}\text { ICOVIR5 } \\
\text { in biopsy }\end{array}$ & $\begin{array}{c}\text { ICOVIR5 in biopsy } \\
\text { Igenomes/mg) }\end{array}$ \\
\hline 001 (CM) & $1 \times 10^{11} \mathrm{vp} / \mathrm{mL}$ & $1 / 1280$ & $>1 / 5120$ & PD & Negative & Negative \\
(genomes/mL)
\end{tabular}

CM, cutaneous melanoma; NA, not available; NAbs, anti-adenovirus neutralizing antibodies; PD: progressive disease, SD: stable disease (until day indicated); UM, uveal melanoma; Vp, viral particles.

${ }^{a}>1 / 5120=$ upper limit of detection..

survival probability was 3.7 times longer for the uveal melanoma patients (Supplementary Fig. S1). Median survival, 271 days for uveal versus 73 days for cutaneous; hazard ratio $0.15 ; 95 \%$ confidence interval 0.026-0.85).

\section{Neutralizing antibodies}

The levels of anti-Ad5 neutralizing antibodies were analyzed before treatment and day 19 posttreatment in sera (Table 3). All patients developed an antiviral immune response as shown by the increase of neutralizing antibodies after virus administration regardless of the basal level and the dose of ICOVIR-5 administered. The increase of titer did not correlate with the dose of ICOVIR-5 administered. Only the 3 patients with lower basal levels of neutralizing antibodies did not reach the upper limit of quantification ( $>5120$ ). Finally, for the highest dose cohort, where stable diseases were seen, no correlation was observed between the preexistence of basal neutralizing antibodies and the stabilization of the disease using Fisher's exact test $(p=1)$.

\section{Virus pharmacokinetics}

Pharmacokinetics of ICOVIR-5 in patients' blood was monitored for the first $24 \mathrm{~h}$ postadministration by quantitative real-time PCR using the specific set of primers for the ICOVIR-5 genome. The level of ICOVIR-5 in blood correlated with the dose administered (Fig. 1). Patient 01, treated with $1 \times 10^{11}$ $\mathrm{vp}$, and patient 03 , treated with $3.3 \times 10^{11} \mathrm{vp}$, had circulating viral genomes up to $1 \mathrm{~h}\left(1.69 \times 10^{4}\right.$ genomes $/ \mathrm{mL})$ and $6 \mathrm{~h}\left(2.85 \times 10^{4}\right.$ genomes $\left./ \mathrm{mL}\right)$ postadministration, respectively (patient 01 had detectable but not quantifiable viral genomes at $6 \mathrm{~h}$ ), with no evidence of viral genomes in blood after $24 \mathrm{~h}$ postadministration. Patient 06, treated with $1 \times 10^{12} \mathrm{vp}$, had quantifiable viral genomes at $6 \mathrm{~h}$ postadministration $\left(1.56 \times 10^{5}\right.$ genomes $\left./ \mathrm{mL}\right)$ and detectable levels at $24 \mathrm{~h}$ postadministration. Patient 07, administered $3.3 \times 10^{12} \mathrm{vp}$, showed quantifiable viral genomes at $24 \mathrm{~h}$ posttreatment $\left(3.61 \times 10^{4}\right.$ genomes/mL). Finally, 5 out of the 6 patients of the last cohort (treated at $1 \times 10^{13} \mathrm{vp}$ ) had quantifiable virus genomes at $24 \mathrm{~h}$ posttreatment $\left(9.18 \times 10^{5}\right.$ genomes $/ \mathrm{mL} \pm 8.67 \times 10^{5}$ genomes/ $\mathrm{mL}$ ), with only one (patient 08 ) with detectable but not quantifiable levels at this time point.

\section{Virus shedding}

In all patients from the lower dose levels (one patient per each dose of $1 \times 10^{11}, 3.3 \times 10^{11}$, and $1 \times 10^{12} \mathrm{vp}$ ), ICOVIR-5 genomes could not be detected in any of the samples analyzed (blood, urine, sputum, and stool).

In patient 07 , treated with $3.3 \times 10^{12} \mathrm{vp}$, virus DNA was detected in blood (although not quantifiable) and in sputum $\left(3.96 \times 10^{3}\right.$ genomes $\left./ \mathrm{mL}\right)$ at $48 \mathrm{~h}$ post-treatment. Both types of samples became negative for the presence of virus in the next time point analyzed, at 5 days posttreatment, and remained negative.

In patients treated at the highest dose level $\left(1 \times 10^{13} \mathrm{vp}\right)$ an increase in the virus shedding was detected (Fig. 2). In blood, at $24 \mathrm{~h}$ posttreatment, 5 out of the 6 patients presented quantifiable viral genomes $\left(9.18 \times 10^{5}\right.$ genomes $/ \mathrm{mL} \pm 8.67 \times 10^{5}$ genomes $/ \mathrm{mL}$ ) and one patient (patient 08) presented detectable but not quantifiable levels. At $48 \mathrm{~h}$ posttreatment, 4 out of 5 patients had quantifiable virus genomes $\left(2.90 \times 10^{5}\right.$ genomes $/ \mathrm{mL} \pm 3.70 \times 10^{5}$ genomes $/ \mathrm{mL}$ ) and one patient (patient 08 ) had detectable but not quantifiable levels. At 5 days posttreatment, 4 out of 6 patients had quantifiable 


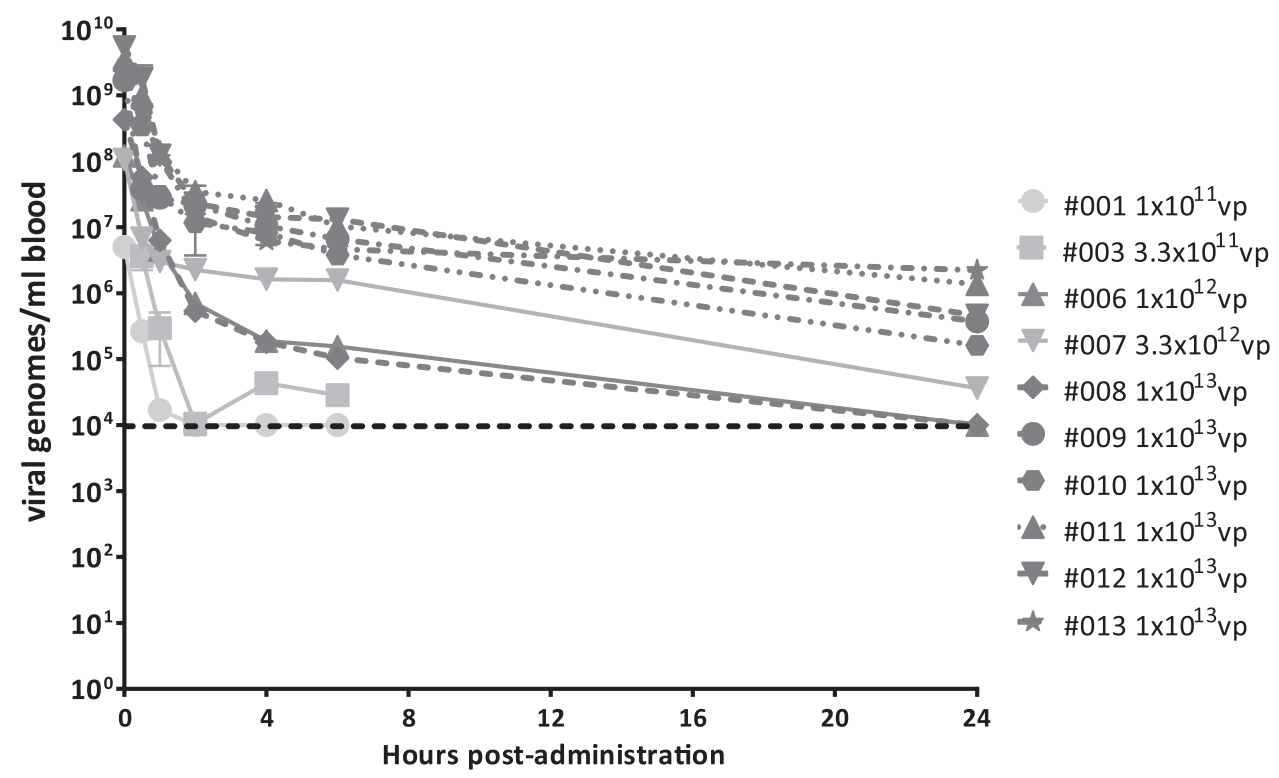

Figure 1. Quantification of ICOVIR-5 pharmacokinetics in blood by real-time PCR. In dose levels 1a, 2a, 3a, and 4a, only viral dose are indicated. For dose level $5 a$, patient number identification is also indicated. The dashed lines represent the lower limit of quantification of ICOVIR-5 genomes in blood. Samples were analyzed in triplicate.

viral genomes $\left(8.64 \times 10^{5}\right.$ genomes $/ \mathrm{mL} \pm 9.94 \times 10^{5}$ genomes $/ \mathrm{mL}$ ) and the remaining 2 patients (patients 08 and 10) had detectable but not quantifiable levels. Virus genomes could be detected up to day 6 (patients 08 and 11) or day 8 (patients 09 and 10) after virus administration. Surprisingly, in the remaining 2 patients (patients 012 and 013), virus genomes were detected until the end of the treatment (day 26 after virus administration).

In urine, virus DNA was detected only in patient 09 . This patient had $1.16 \times 10^{6}$ genomes $/ \mathrm{mL}$ at $24 \mathrm{~h}$, $1.51 \times 10^{5}$ genomes $/ \mathrm{mL}$ at $48 \mathrm{~h}$, and $2.16 \times 10^{5}$ genomes/mL at day 5 after treatment. In stool, at $24 \mathrm{~h}$ postadministration, virus genomes were detected in 4 out of 4 patients analyzed (patients 09, 010, 011 , and $012 ; 5.89 \times 10^{4}$ genomes $/ g \pm 4.35 \times 10^{4}$ genomes/g); at $48 \mathrm{~h}$ postadministration, virus was detected in 2 (09 and 012) out of 3 (patients 09, 010 , and 012$)$ and analyzed $\left(6.98 \times 10^{4}\right.$ genomes/ $\mathrm{g} \pm 3.90 \times 10^{4}$ genomes/g); and at day 5 postadministration, virus was detected in 1 (patient 013 ) out of 3 (patients 09,012 , and 013 ) but did not reach a quantifiable level.

Finally, in sputum at $24 \mathrm{~h}$ postadministration, viral genomes were detected in 2 (patients 09 and 010) out of 3 (patients 08, 09, and 010) samples analyzed $\left(6.09 \times 10^{4}\right.$ genomes $/ \mathrm{mL} \pm 5.87 \times 10^{4}$ genomes/mL) and at $48 \mathrm{~h}$ post-administration in 2 (patients 010 and 012 ) out of 4 (patients $08,09,010$, and 012$)$ samples analyzed $\left(3.43 \times 10^{4}\right.$ genomes $/ \mathrm{mL}$ and one not quantifiable); and at day 5 post- administration in 1 (patient 012) out of 5 (patients 08, 09, 010, 012, and 013) samples analyzed $\left(3.91 \times 10^{4}\right.$ genomes $\left./ \mathrm{mL}\right)$. All samples from days 12 , 19 , and 26 were negative.

\section{Cytokine analysis}

Analysis of serum interleukin 6 (IL6) and IL10 levels was performed before and after treatment (at $6 \mathrm{~h}, 24 \mathrm{~h}, 48 \mathrm{~h}$, day 5 , day 12 , day 19 , and day 26 post-ICOVIR-5 administration) (Fig. 3). An increase of IL6 levels was detected for all patients in the first $24 \mathrm{~h}$ postadministration, likely reflecting an early innate immune response against the virus. At $6 \mathrm{~h}$ postadministration, there was a correlation between the viral dose used and the IL6 level detected $\left(22.6 \mathrm{pg} / \mathrm{mL}\right.$ for $1 \times 10^{11} \mathrm{vp}, 28.8 \mathrm{pg} / \mathrm{mL}$ for $3.3 \times 10^{11} \mathrm{vp}, 31.5 \mathrm{pg} / \mathrm{mL}$ for $1 \times 10^{12} \mathrm{vp}, 49.9 \mathrm{pg} / \mathrm{mL}$ for $3.3 \times 10^{12} \mathrm{vp}$, and a mean of $303 \mathrm{pg} / \mathrm{mL}$ for $1 \times 10^{13} \mathrm{vp}$; lineal regression IL6 concentration versus amount of ICOVIR-5 administered, $r=0.97$, $p<0.005)$. The peak of IL6 level observed for most patients was lower than $100 \mathrm{pg} / \mathrm{mL}$. Only 3 patients showed a peak higher than $200 \mathrm{pg} / \mathrm{mL}$ (patients 01, 08, and 010). Among them, only in patient $08\left(1 \times 10^{13} \mathrm{vp}\right)$ this higher IL6 elevation was accompanied with a dose-limiting toxicity, as a transaminitis grade 3 at $24 \mathrm{~h}$ posttreatment.

Serum IL10 was also measured, as it is another biomarker of inflammation commonly detected upon systemic adenovirus administrations, although with antiinflammatory properties contrary 


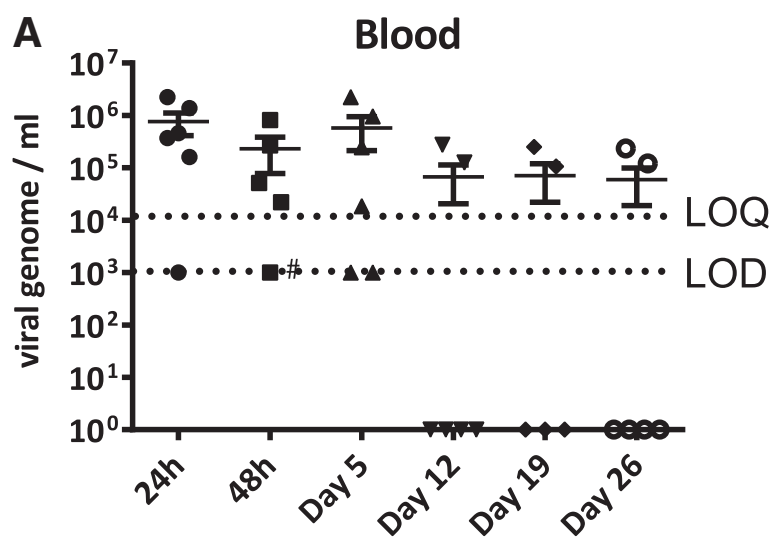

Time after ICOVIR-5 administration

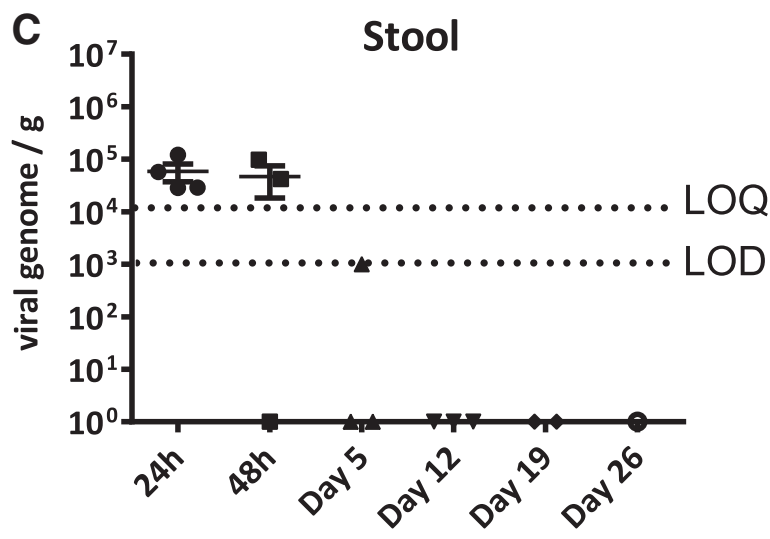

Time after ICOVIR-5 administration

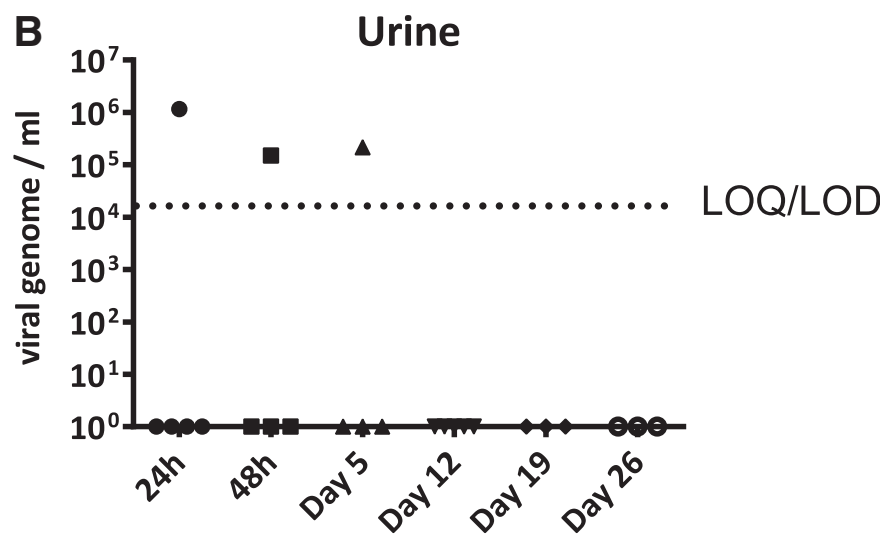

Time after ICOVIR-5 administration

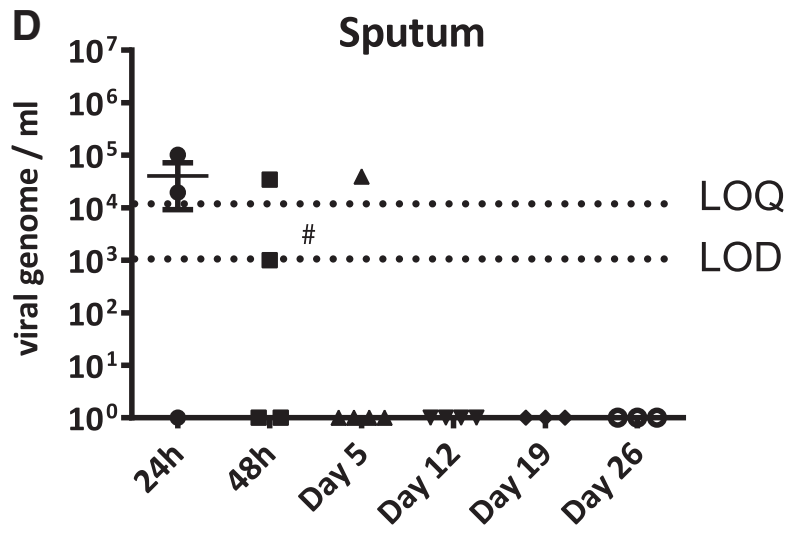

Time after ICOVIR-5 administration

Figure 2. Quantification of ICOVIR-5 genomes in high-dose patients $\left(1 \times 10^{13} \mathrm{vp}\right)$ by real-time PCR in blood (A), urine (B), stool (C), and sputum (D). The dashed lines represent the lower limit of quantification (LOO) and detection (LOD) of ICOVIR-5 genomes. Samples were analyzed in triplicate. \# indicates detectable but not quantifiable sample.

to the proinflammatory IL6. A peak of IL10 was detected in all patients, reaching higher peaks levels with higher doses. As previously reported, the peak of IL10 $(24 \mathrm{~h})$ was delayed compared to IL6 $(6 \mathrm{~h}) .{ }^{15}$ At $24 \mathrm{~h}$ postadministration, there was a correlation between the viral dose and the IL10 level detected (lineal regression IL10 concentration versus amount of ICOVIR-5 administered, $r=0.81$; $\mathrm{p}<0.05)$. Patient $013\left(1 \times 10^{13} \mathrm{vp}\right)$ had the highest IL10 peak $(530 \mathrm{pg} / \mathrm{mL})$ and showed a dose-limiting toxicity as a transaminitis grade 3 at $24 \mathrm{~h}$ posttreatment. There was a correlation of IL6 levels at $6 \mathrm{~h}$ and IL10 at $24 \mathrm{~h}(r=0.93 ; p<0.05)$.

\section{Detection of ICOVIR-5 in tumor biopsies}

One core needle biopsy was obtained from skin lesions of cutaneous melanoma patients and liver lesions of uveal melanoma patients. Biopsies were obtained at day 5 posttreatment in patients treated with $1 \times 10^{11} \mathrm{vp}, 3.3 \times 10^{11} \mathrm{vp}, 3.3 \times 10^{12} \mathrm{vp}$, and 3 (patients 09, 011, and 013) out of the 6 patients from the highest dose of $1 \times 10^{13} \mathrm{vp}$. DNA was extracted from biopsies and the presence of viral genomes analyzed by qPCR using specific primers for ICOVIR-5. Virus DNA in metastasis was not detected in the patient treated with the lower $1 \times 10^{11}$ vp dose. In contrast, virus DNA was detected in patients treated with $3.3 \times 10^{11} \mathrm{vp}$ and $3.3 \times 10^{12} \mathrm{vp}$, and in 2 (patients 09 and 011 ) out of 3 patients from the highest $1 \times 10^{13} \mathrm{vp}$ dose (Table 3 ). In these 2 patients the presence of virus DNA in blood at the time of biopsy (day 5 postadministration) precludes a clear conclusion on tumor transduction. However, in the 2 patients with lower virus doses $\left(3.3 \times 10^{11} \mathrm{vp}\right.$ and $3.3 \times 10^{12} \mathrm{vp}$ ) no viral DNA was detected in peripheral blood at day 5 postadministration, suggesting that the detected virus derives from tumor cells and not from blood. 

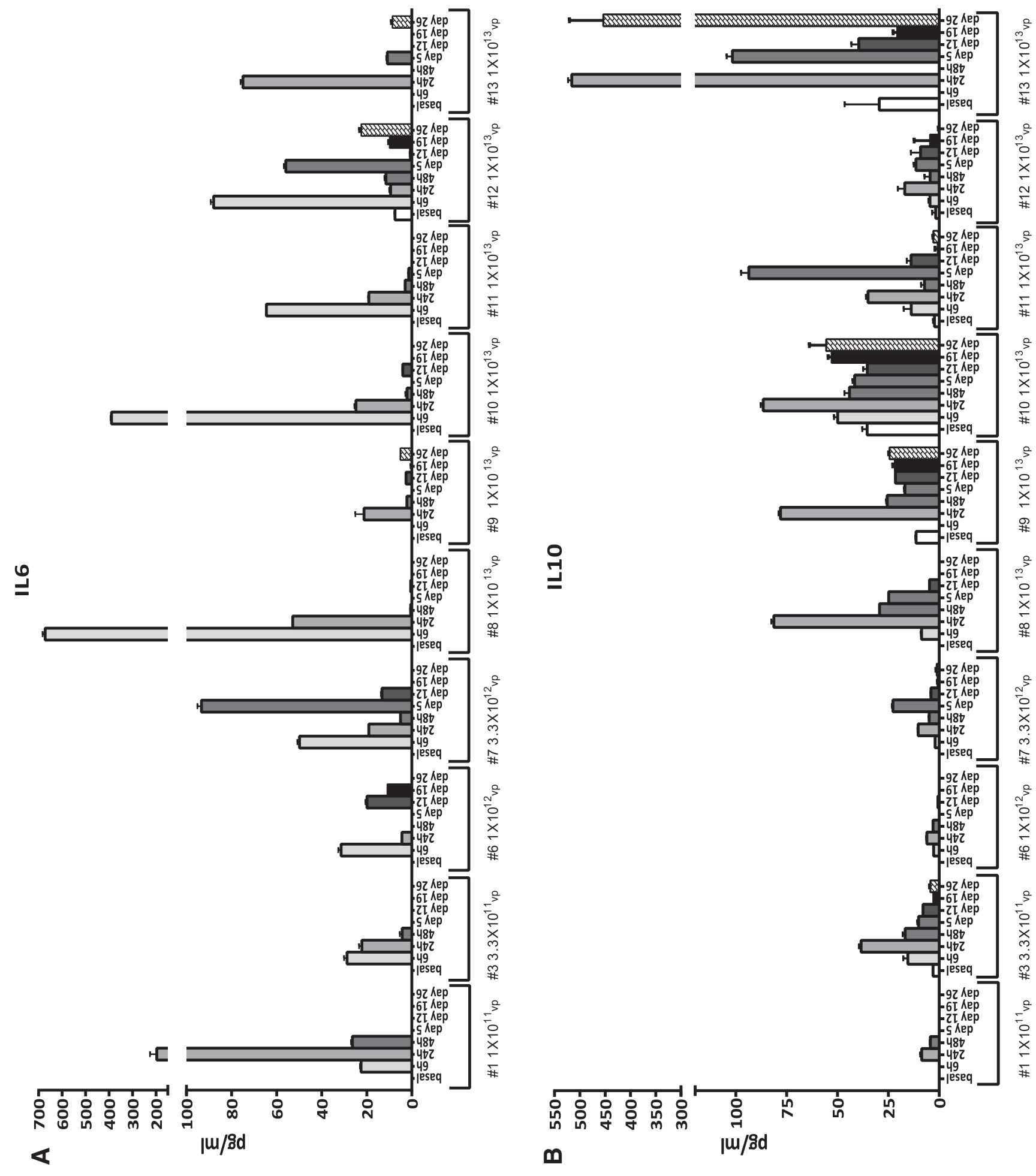


\section{DISCUSSION}

The use of oncolytic viruses to treat cancer, known as virotherapy, is an old idea born after the observation of cancer remissions upon viral infections. ${ }^{16}$ After up and downs, the concept has been revisited in the last 20 years using viruses such as vaccinia virus, herpes simplex virus, measles, and adenoviruses designed to target and replicate more selectively in cancer cells and wild type viruses with a natural selectivity for tumor cells such as reovirus, parvovirus, or coxsackievirus A21, among others. Intratumoral injection of these viruses in patients has proven the concept that when a virus reaches a tumor mass it can cause tumor lysis. ${ }^{17}$ However, tumor targeting upon systemic administration is still a challenge.

This first-in-humans phase 1 study shows that the intravenous administration of the conditionally replicative adenovirus ICOVIR-5 is well tolerated. A dose of $1 \times 10^{13} \mathrm{vp}$ of ICOVIR-5 induced transaminitis in 2 out of 6 patients, and thrombocytopenia in one of them, while a dose of $3.3 \times 10^{12} \mathrm{vp}$ can be safely administered without DLT. The primary objective of the trial was to recommend a phase 2 dose. According to the protocol, the dose level in which no DLT was observed would be taken as a safe dose level and therefore the recommended phase 2 dose. Our results indicate that for ICOVIR5 this dose is $3.3 \times 10^{12} \mathrm{vp}$. Mild liver toxicity has been previously described with similar intravenously administered viruses. ${ }^{15,18,19}$ ICOVIR-7, an oncolytic adenovirus similar to ICOVIR-5, produced up to grade 2 liver transaminases elevation in 13 of 21 patients, although most of the patients received treatment by intratumoral injection, and only 3 intravenously. ${ }^{20}$ For ICOVIR-5, transaminitis was the main toxicity, limiting the dose escalation beyond the $1 \times 10^{13} \mathrm{vp}$ dose. This transient transaminitis, observed in 2 patients, started at days 1 and 5 posttreatment and persisted for 1 and 7 days, respectively.

Systemic administration has been attempted in clinical trials using Newcastle disease virus, herpes simplex virus, reovirus, picornavirus, measles, vaccinia virus, ${ }^{21}$ and adenovirus. ${ }^{19}$ Out of 8 evaluated patients in a recent trial of an oncolytic vaccinia virus administered systemically, 2 proved positive for virus in biopsy. ${ }^{21}$ Still, the inadequate viral delivery was identified as a main factor for insufficient antitumor efficacy. Adenovirus has been extensively used in gene therapy and virotherapy clinical trials. Among several clinical trials with systemically administered Onyx015, only occasional and transient responses were observed in some colorectal carcinoma patients. ${ }^{22,} 23$
With CG7870, an oncolytic adenovirus designed for prostate carcinoma with E1A under the probasin promoter and E1B under the prostate-specific antigen (PSA) promoter, the serum PSA level dropped $25 \%$ to $49 \%$ transiently in 5 out of the 23 intravenously treated patients- 4 of them at the highest doses $\left(6 \times 10^{11}\right.$ to $\left.6 \times 10^{12} \mathrm{vp}\right){ }^{19}$

Focusing on tumor targeting, occasional evidence for systemic tumor targeting has been reported. Reid et al. injected ONYX-015 intraarterially in 11 patients with liver metastases of colorectal cancer, and biopsies at day 4 postinfusion produced negative results for virus. ${ }^{22}$ Similar results were obtained in the phase 2 trial after infusing $2 \times 10^{12} \mathrm{vp}$ as a maximum feasible dose on multiple days $(1,8,22,50$, and 78$) .{ }^{23}$ It was concluded that improved delivery and replication efficiency would be needed to obtain evidences of intratumoral replication. Hamid et al. used intravenously infused ONYX-015 for 18 patients with liver metastases of colorectal carcinoma. ${ }^{18}$ The autopsy of one patient that died $56 \mathrm{~h}$ after virus administration showed very few cells positive for virus in the tumors. Nemunaitis et al. infused ONYX-015 intravenously in 10 patients with lung metastases, reaching much higher doses (up to $2 \times 10^{13} \mathrm{vp}$ ). One analyzed biopsy in a patient treated with $2 \times 10^{12} \mathrm{vp}$ was positive for virus presence 5 days postinfusion. ${ }^{15} \mathrm{~A}$ more potent virus, CG7870, where E1A and E1b were regulated by the probasin and the PSA promoters respectively, was infused intravenously in prostate carcinoma patients up to a dose of $6 \times 10^{12} \mathrm{vp}$, identified as the MTD, but no biopsies were analyzed for tumor targeting. ${ }^{19}$

Lack of antitumor efficacy in these clinical trials led to abandonment of the systemic approach with oncolytic adenoviruses based on adenovirus serotype 5 with an unmodified capsid. After an interval of several years, a survey of clinical trials ongoing in 2014 identified ICOVIR-5, ColoAd1, and VCN01 (all of them with capsids different from Ad5 wild type) as oncolytic Ads used intravenously, and no additional adenoviruses were added to this list in $2015 .^{24,} 25$ However, the Ad-D24RGD oncolytic adenovirus, with the same RGD-modified capsid as ICOVIR-5, has been used intratumorally, ${ }^{26}$ intraperitoneally, ${ }^{27}$ and in a combination of intratumoral and intravenous routes. ${ }^{20,28}$ Evidence of systemic tumor targeting in noninjected tumors distant from injected tumors was observed in an autopsy of one patient (C200) who died 19 days after injection in multiple tumor sites. ${ }^{28}$ With regard to oncolytic adenoviruses with other capsid modifications, metastatic tumor targeting has been demonstrated in a 
patient treated intravenously with a serotype $5 / 3$ chimeric fiber. ${ }^{28}$ The biodistribution analysis in patient autopsy samples indicated a fair capability of tumor targeting of oncolytic adenoviruses even when injected intratumorally. ${ }^{28}$ This consistent detection of virus in occasional patient autopsies suggests that the small samples that can be analyzed in a biopsy may underestimate the tumor targeting potential of the virus. In this context our detection of viral genomes in four out of seven analyzed biopsies, in two cases with a negative viremia, is noteworthy. The same can be concluded from the more frequently reported observation of secondary peaks of viremia compared to positive biopsies, which suggest virus replication in tumors. We did not observe secondary peaks of viremia even in the four patients where the virus had been detected in the tumor at day 5. In 2 patients (012 and 013) viremia levels were positive until the end of the study (day 26). Among them, only patient 013 had a tumor biopsy analyzed at day 5, with negative results. Although preliminary, our results indicate that the presence of virus in the tumor does not necessarily leads to secondary peaks of viremia.

In our study, pharmacokinetics analysis indicates that there is a correlation between exposure and the administered dose, since larger doses lead to longer time to virus elimination. In addition, the study shows that the virus shedding is also dose dependent: the presence of the virus is higher in the last dose level, but at the recommended dose level it is found in blood and sputum at $48 \mathrm{~h}$, indicating effective spread of the virus. The analysis shows that neutralizing antibody titers were not dose-dependent and pretreatment levels did not correlate with tumor response. All patients had an early onset of innate immune response, with a correlation between dose and levels of IL6. As reported, the peak of IL10 was delayed compared with IL6. IL6 and IL10 levels correlated with the dose and between them. Patients with grade 3 transaminitis (patients 08 and 013) showed the highest peaks of IL6 and IL10. This toxicity was very short in time and no systemic inflammatory response syndrome was observed.

As a most relevant finding, viral genomes were detected in the biopsy of metastatic lesions of 4 patients, indicating that oncolytic adenovirus can achieve tumor targeting of metastases upon intravenous administration. With regard to clinical activity, no tumor responses were observed, but seven stabilizations of disease were seen out of 11 patients, five of them among the 6 patients treated at the highest dose. Despite this low antitumor activity, the longer survival of uveal melanoma patients compared with cutaneous melanoma patients was intriguing, as the expected survival before the emergence of targeted therapy (BRAF/ MEK inhibitors) and anti-PD1 antibodies for those patients should be the same. ${ }^{29}$ Although the number of patients is very small and definitive conclusions cannot be taken, this trend suggests a superior activity of systemic ICOVIR5 against metastatic uveal melanoma compared to metastatic cutaneous melanoma. It could be speculated that this could be related to the shared hepatotropism of adenovirus and uveal melanoma metastases or/and that uveal melanoma liver metastases are more prone to be controlled by the immune system once infected by the virus.

Low antitumor efficacy has been previously reported with oncolytic adenoviruses. By intratumoral administration to head and neck patients, ONYX-015 produced 3 partial and 2 minor responses and 8 disease stabilizations. ${ }^{30}$ In 23 pancreatic cancer patients, it produced 6 minor responses and 10 stabilizations. ${ }^{31}$ In the phase 1 study of intratumoral Telomelysin in various solid tumors, 1 partial and 7 stable disease responses were reported. ${ }^{32}$ By intraperitoneal injection of Ad5- $\Delta 24$ RGD, 15 disease stabilizations were observed among 21 malignant gynecologic patients. ${ }^{27} \mathrm{Fi}-$ nally, among 35 noninvasive bladder cancer patients receiving CG0070 intravesically, 17 showed complete responses. ${ }^{33}$ By intravenous administration, ONYX-015 induced one mixed response and nine disease stabilizations in 10 patients. ${ }^{15}$ In a subsequent phase 2 trial, 7 out of 18 patients experienced stable disease. ${ }^{18}$ Systemic administration of CG7870 in 23 prostate cancer patients induced some decrease in serum PSA in 5 patients, with no complete or partial PSA responses. ${ }^{19}$ With ICOVIR7, ${ }^{20}$ out of 2 evaluated patients that were treated only by the intravenous route, a single head and neck tumor patient had a $10 \%$ decrease in tumor size.

There is little experience with oncolytic adenoviruses applied to melanoma, and none after systemic administration alone. When oncolytic adenovirus Ad5/3-D24-GMCSF was administered to 9 patients with melanoma $(50 \%$ of dose intratumoral and 50\% intravenous), 1 out of 4 evaluable patients showed a minor response (15\% size decrease) in an injected lesion. ${ }^{34}$

Our study adds interesting information to the development of virotherapy with oncolytic adenoviruses. One point of growing interest is the potential combination of oncolytic viruses with immunotherapy, as the virus-induced immune response may favor the infiltration of lymphocytes in 
tumors. In this setting, it is imperative for the virus to reach all tumor sites systemically to promote the infiltration of "cold" tumors characterized by the lack of tumor-infiltrating lymphocytes. Our results indicate that systemic tumor targeting of metastases with oncolytic adenoviruses is feasible using the intravenous administration route. Although armed oncolytic adenoviruses may be needed to obtain sufficient tumor debulking by oncolysis before antiviral immunity neutralizes the virus, our results encourage further studies by systemic administration. We are currently exploring the use of a hyaluronidase-armed oncolytic adenovirus (VCN01) with a slightly different capsid than ICOVIR-5 (RGD in the fiber shaft instead of the HI-loop) by systemic administration in cancer patients.

\section{ACKNOWLEDGMENTS}

This work was supported by EC-08-00136 grant from the Ministerio de Economia y Competitividad of Spain. It was co-funded by the European Regional Development Fund, a way to Build Europe. Thanks to Mei Zhuyong, Deborah L. Lyon, and Suzanne M. Poole from the Center for Cell and Gene Therapy at Baylor College of Medicine for GMP production of ICOVIR-5; Institut Catala d'Oncologia nurses Olimpia Garcia and Susana Lorente for car- ing of patients; Maria Perayre from the ICO Pharmacy for her support in ICOVIR-5 storage and processing; Enric Espunya, Nuria Arilla, and Josep Ferrés from HIPRA for importing ICOVIR-5; Isabel Gomez at Institut de Investigacio Biomedica de Bellvitge and Nuria Benitez at ICO for project management; Mercè Monfar and Miguel Chillon from the Vector Unit Production of the Center of Animal Biotechnology and Gene Therapy of Bellaterra for ICOVIR-5 production and characterization; Manuel Ramirez, Luis Madero, and Javier García Castro for sharing Ministerio de Economia y Competitividad EC-07-90591 and EC-08-00094 grants for copayment for GMP ICOVIR-5 production; and Sol Ruiz from the Spanish Drug Agency for regulatory guidance. Trial reference EudraCT 2008005694-35 and ClinicalTrials.gov Identifier: NCT01864759. IND reference PEI 09-024.

\section{AUTHOR DISCLOSURE}

No competing financial interests exist.

\section{SUPPLEMENTARY MATERIAL}

\author{
Supplementary Table S1 \\ Supplementary Figure S1
}

\section{REFERENCES}

1. International Agency for Research on Cancer. GLOBOCAN 2012. Estimated cancer incidence, mortality, and prevalence worlwide in 20122012. Lyon, France: International Agency for Research on Cancer. http://globocan.iarc.fr (last accessed July 1, 2016).

2. Chapman PB, Einhorn LH, Meyers ML, et al. Phase III multicenter randomized trial of the Dartmouth regimen versus dacarbazine in patients with metastatic melanoma. J Clin Oncol 1999;17:2745-2751.

3. Hauschild A, Grob JJ, Demidov LV, et al. Dabrafenib in BRAF-mutated metastatic melanoma: a multicentre, open-label, phase 3 randomised controlled trial. Lancet 2012;380:358-365.

4. Flaherty KT, Robert C, Hersey P, et al. Improved survival with MEK inhibition in BRAF-mutated melanoma. N Engl J Med 2012;367:107-114.

5. Long GV, Stroyakovskiy D, Gogas H, et al. Combined BRAF and MEK inhibition versus BRAF inhibition alone in melanoma. N Engl J Med 2014; 371:1877-1888.

6. Hodi FS, O'Day SJ, McDermott DF, et al. Improved survival with ipilimumab in patients with metastatic melanoma. N Engl J Med 2010;363:711-723.

7. Robert C, Long GV, Brady B, et al. Nivolumab in previously untreated melanoma without BRAF mutation. N Engl J Med 2015;372:320-330.
8. Robert C, Ribas A, Wolchok JD, et al. Antiprogrammed-death-receptor-1 treatment with pembrolizumab in ipilimumab-refractory advanced melanoma: a randomised dose-comparison cohort of a phase 1 trial. Lancet 2014;384:11091117

9. Andtbacka RH, Kaufman HL, Collichio F, et al. Talimogene laherparepvec improves durable response rate in patients with advanced melanoma. J Clin Oncol 2015;33:2780-2788.

10. Uusi-Kerttula H, Hulin-Curtis S, Davies J, et al. Oncolytic Adenovirus: strategies and insights for vector design and immuno-oncolytic applications. Viruses 2015;7:6009-6042.

11. Alemany R, Cascallo M. Oncolytic viruses from the perspective of the immune system. Future Microbiol 2009;4:527-536.

12. Suzuki K, Fueyo J, Krasnykh V, et al. A conditionally replicative adenovirus with enhanced infectivity shows improved oncolytic potency. Clin Cancer Res 2001;7:120-126.

13. Cascallo M, Alonso MM, Rojas JJ, et al. Systemic toxicity-efficacy profile of ICOVIR-5, a potent and selective oncolytic adenovirus based on the pRB pathway. Mol Ther 2007;15:1607-1615.

14. Alemany R, Curiel DT. CAR-binding ablation does not change biodistribution and toxicity of adenoviral vectors. Gene Ther 2001;8:1347-1353.
15. Nemunaitis J, Cunningham $C$, Buchanan $A$, et al. Intravenous infusion of a replication-selective adenovirus (ONYX-015) in cancer patients: safety, feasibility and biological activity. Gene Ther 2001; 8:746-759.

16. Russell SJ, Peng KW, Bell JC. Oncolytic virotherapy. Nat Biotechnol 2012;30:658-670.

17. Kaufman HL, Kohlhapp FJ, Zloza A. Oncolytic viruses: a new class of immunotherapy drugs. Nat Rev Drug Discov 2015;14:642-662.

18. Hamid 0, Varterasian ML, Wadler S, et al. Phase II trial of intravenous $\mathrm{Cl}-1042$ in patients with metastatic colorectal cancer. J Clin Oncol 2003; 21:1498-1504.

19. Small EJ, Carducci MA, Burke JM, et al. A phase I trial of intravenous CG7870, a replicationselective, prostate-specific antigen-targeted oncolytic adenovirus, for the treatment of hormonerefractory, metastatic prostate cancer. Mol Ther 2006;14:107-117.

20. Nokisalmi P, Pesonen S, Escutenaire S, et al. Oncolytic adenovirus ICOVIR-7 in patients with advanced and refractory solid tumors. Clin Cancer Res 2010;16:3035-3043.

21. Downs-Canner S, Guo ZS, Ravindranathan R, et al. Phase 1 study of intravenous oncolytic poxvirus (vvDD) in patients with advanced solid cancers. Mol Ther 2016;24:1492-1501. 
22. Reid T, Galanis E, Abbruzzese J, et al. Intraarterial administration of a replication-selective adenovirus (d11520) in patients with colorectal carcinoma metastatic to the liver: a phase I trial. Gene Ther 2001:8:1618-1626.

23. Reid T, Galanis E, Abbruzzese J, et al. Hepatic arterial infusion of a replication-selective oncolytic adenovirus (dl1520): phase II viral, immunologic, and clinical endpoints. Cancer Res 2002;62:6070-6079.

24. Pol J, Bloy N, Obrist F, et al. Trial Watch: OncoIytic viruses for cancer therapy. Oncoimmunology 2014:3:e28694

25. Pol J, Buque A, Aranda F, et al. Trial Watch: Oncolytic viruses and cancer therapy. Oncoimmunology 2016;5:e1117740.

26. Lang FF, Conrad C, Gomez-Manzano C, et al. Phase I clinical trial of oncolytic virus delta-24-RGD (DNX2401) with biological endpoints: implications for viroimmunotherapy. Neuro Oncol 2014;16:v159-v167.

27. Kimball KJ, Preuss MA, Barnes MN, et al. A phase I study of a tropism-modified conditionally replicative adenovirus for recurrent malignant gynecologic diseases. Clin Cancer Res 2010;16: 5277-5287.

28. Koski A, Bramante S, Kipar A, et al. Biodistribution analysis of oncolytic adenoviruses in patient autopsy samples reveals vascular transduction of noninjected tumors and tissues. Mol Ther 2015; 23:1641-1652.

29. Kuk D, Shoushtari AN, Barker CA, et al. Prognosis of mucosal, uveal, acral, nonacral cutaneous, and unknown primary melanoma from the time of first metastasis. Oncologist 2016;21: 848-854.

30. Ganly I, Kirn D, Eckhardt G, et al. A phase I study of Onyx-015, an E1B attenuated adenovirus, administered intratumorally to patients with recurrent head and neck cancer. Clin Cancer Res 2000; 6:798-806.

31. Mulvihill S, Warren R, Venook A, et al. Safety and feasibility of injection with an E1B-55 kDa genedeleted, replication-selective adenovirus (ONYX-
015) into primary carcinomas of the pancreas: a phase I trial. Gene Ther 2001;8:308-315.

32. Nemunaitis J, Tong AW, Nemunaitis M, et al. A phase I study of telomerase-specific replication competent oncolytic adenovirus (telomelysin) for various solid tumors. Mol Ther 2010;18:429-434.

33. Burke JM, Lamm DL, Meng MV, et al. A first in human phase 1 study of CG0070, a GM-CSF expressing oncolytic adenovirus, for the treatment of nonmuscle invasive bladder cancer. J Urol 2012; 188:2391-2397.

34. Bramante S, Kaufmann JK, Veckman V, et al Treatment of melanoma with a serotype $5 / 3$ chimeric oncolytic adenovirus coding for GM-CSF results in vitro, in rodents and in humans. International journal of cancer 2015;137:1775-1783.

Received for publication May 25, 2018; accepted after revision September 16, 2018

Published online: September 17, 2018. 